\title{
La estructura de poder del BID
}

\section{INTRODUCGIÓN}

En la década del 50 se hace imprescindible para América Latina so lucionar un gran número de problemas que eran limitantes para su desarrollo económico y cuya solución no podían lograr los países por sí solos. Desde principios de siglo se venía tratando de crear un organismo internacional que pudiera cooperar en la solución de los problemas sociales generados por variados factores, identificando como el principal a la falta de financiamiento para la ejecución de proyectos que contribuyeran a acelerar el proceso de desarrollo económico social.

Hasta casi fines de la década del 50 la agenda de Estados Unidos con respecto a América Latina tuvo una prioridad en los asuntos de seguridad del continente, especificamente en lo relacionado con asuntos de tipo político-militar. Las diferentes administraciones norteamericanas asumieron que todos los temas por tratar deblan basarse en los componentes de la balanza de poder, actuales o futuros, y los asuntos que se percibieran como amenaza a la seguridad del Estado. Otras materias podrían ser consideradas sólo si afectaban la seguridad y el poder militar.

El descontento latinoamericano se hizo presente cuando el Vicepresidente y otras autoridades de Estados Unidos visitaron Latinoamérica, recibiendo manifestaciones populares de repudio por la politica de relaciones internacionales norteamericanas hacia el hemisferio. El Presidente de Brasil, Juscelino Kubitscheck, logra politizar estas aspiraciones en un documento conocido como la Operación Panamericana, convenciendo con ello a la administración norteamericana de que esto; problemas debfan ser tratados en sus agendas porque las consecuencias de su falta de preocupación los afectarían por igual. Logrado el apoyo norteamericano para la búsqueda de la solución de los problemas, se organiza y sistematiza la cooperación entre el país más desarrollado de la región y los países menos desarrollados, dando origen al Banco Interamericano de Desarrollo.

El BID fue creado, para dar una solución técnica a los múltiples problemas de desarrollo social y económico de la región, como un 
mecanismo de cooperación que buscaba la obtención de un fin específico: "el desarrollo económico y social, individual y colectivo de los países miembros regionales en vías de desarrollo". La palabra colectivo indica la prioridad que el BID le asignó desde sus origenes a la integración, no tan sólo como un apoyo a esos procesos, sino dando prioridad a aquellos proyectos que tenían un componente integracionista. Esta prioridad es lo que permite asimilar la función del Banco a la corriente funcionalista por estar intimamente relacionado con la teoría funcionalista de integración de comunidades.

Este trabajo tratará de demostrar que el BID se asimila a esta visión funcionalista, que formula que los sistemas políticos nacionales son inadecuados para resolver muchos problemas por la naturaleza interdependiente del mundo moderno y que por lo: tanto es obvio que la solución de los problemas técnicos a nivel regional o mundial deben ser resueltos por organismos técnicos internacionales.

\section{LAS ALTERNATIVAS PARA CONFORMAR SU ESTRUCTURA}

Ya en 1889-1890, durante la Primera Conferencia Internacional Americana, surge la idea de crear un organismo financiero internacional, idea que continúa vigente en varias conferencias internacionales americanas realizadas con posterioridad. En 1940, el Comité Consultivo Económico y Financiero Interamericano formado por 21 expertos, adopta la resolución de recomendar su creación, constituyendo el primer esfuerzo concreto de crear un organismo financiero regional. Hay otros intentos de crear un Banco de Desarrollo entre 1948 y 1955, pero no existe el consenso entre los países latinoamericanos. En 1958 hay un empeoramiento de la situación económica latinoamericana, que se demuestra por las manifestaciones populares en contra de las visitas del Vicepresidente de Estados Unidos Richard Nixon, el Secretario del Tesoro y el hermano del Presidente, doctor Milton Eisenhower.

EI Presidente de Brasil Juscelino Kubitcheck inicia una campaña destinada a revisar y esclarecer los objetivos de los ideales panamericanos, elaborando un documento conocido como la "Operación Panamericana", con un gran impacto favorable en las élites latinoamericanas, y logrando hacer cambiar la actitud norteamericana y obtener su apoyo para el establecimiento de una institución americana de desarrollo regional.

Los objetivos de la Operación Panamericana fueron tratados en una reunión informal de Ministros de Relaciones Exteriores celebrada en Washington en 1958, creando una comisión especial "Comité de los 21", que se encarga de la negociación y redacción del Convenio Constitutivo. La Comisión Especializada termina su ta- 
rea en abril de 1959 con un acta final, siendo convocada la Primera Reunión de Gobernadores del BxD el 16 de febrero de 1960.

\section{LA TEORÍA POLÍTIGA Y LA GREAGIÓN DEL BID}

El funcionalismo es una visión de las relaciones internacionales que se opone a la visión clásica o realista, por cuanto formula que la creación de redes transnacionales de organizaciones económicas y sociales permitirá la solución de problemas, haciendo cambiar la actitud de las personas al predisponerlas a la cooperación y ser contrarias a la confrontación.

Los funcionalistas sostienen que las relaciones internacionales:

- Son protagonizadas por un creciente número de centros de poder.

- Los temas tratados a nivel internacional no sólo representan los intereses del Estado; también los de la sociedad civil organizada.

- La agenda internacional es más compleja y menos jerarquizada.

- Se ponen en juego recursos de poder no tradicionales.

Por ello sostienen que ya no hay un centro-periferia y que el sistema internacional se ha funcionalizado. El mundo moderno le da una gran importancia al proceso de transnacionalización y a las relaciones de interdependencia que interactúan a través de agentes gubernamentales o no gubernamentales.

En el funcionalismo hay dos corrientes: Ios funcionalistas y los neofuncionalistas, con diferencias conceptuales entre ellos. Los funcionalistas le dan poca importancia al poder y a la política y mucha a las organizaciones supranacionales, manifestando además que la actividad funcional hará que los técnicos reemplacen a los políticos. En cambio los neofuncionalistas se refieren a comunidades menoș formales y difieren en cuanto a que los técnicos reemplazarán a los políticos; lo que sí sugieren, es que los requerimientos del funcionalismo conducirán a una nueva forma de acción pol'tica. La diferencia fundamental es que los neofuncionalistas plantean hipótesiṣ sobre la integración con una elaboración, modificación y prueba diferente, basada principalmente en la evolución de la Comunidad Económica Europea.

IV. EL BID GOMO RESULTADO DE UN PROCESO INTEGRATIVO

1. Condiciones para conformar un proceso integrativo: Según lo. neofuncionalistas existen tres condic ones para que se realice un esquema integrativo y ellas son: 
a) El amalgama político o el desarrollo de instituciones centrales en un esquema integrativo, incluyendo dos o más Estados. La forma de medir este factor es analizando si las instituciones existentes son capaces de hacer decisiones conjuntas. EI BID hasta 1988 ha sido capaz a través de la Asamblea de Gobernadores y de su Directorio Ejecutivo de llevar adelante todas las políticas de financiamiento de desarrollo que se han impuesto. El origen del BID se basó en un consenso de 18 países latinoamericanos, logrando aumentar sus miembros en la actualidad a cuarenta y cuatro Naciones-Estado. El BID actualmente está en crisis con respecto a su recapitalización, pero ésta no ha afectado a sus organismos superiores en cuanto a Ios mecanismos decisionales, aunque esta es una materia de negociación que desea imponer su principal accionista.

b) Cooperación Intergubernamental: Ella se desarrolla en tres planos: A nivel organización-gobierno en forma de financiamiento para el desarrollo de proyectos socio-económicos, o bien como cooperación técnica en sectores especfficos; capitalizando y coordinando la cooperación intergubernamental de gobierno a gobierno en aspectos tecnológicos; y por último, la cooperación no sólo se limita a nivel gobierno, sino también en forma directa hacia los sectores productivos privados a través de la Corporación Interamericana de Inversiones, cuya función es estimular el establecimiento, ampliación y modernización de la empresa privada.

c) Información a la mayoría de la comunidad para que adhieran al proceso: El BID organiza mesas redondas, seminarios y foros internacionales a los cuales invita a funcionarios gubernamentales y organizaciones privadas para el análisis y discusión de temas de desarrollo e integración. El resultado y. las conclusiones de estas reuniones las da a conocer a través de folletos, libros y revistas que son distribuidos a las instituciones académicas y de desarrollo nacional a través de las Representaciones que mantiene en cada país miembro. De esta forma concita el interés en la función que desarrolla como único organismo financiero regional con capacidad técnica y financiera para la solución de problemas de desarrollo.

2. Mecanismos de un proceso de cooperación: Joseph Nye, teórico neofuncionalista, ha desarrollado un modelo en el que formula los mecanismos que actúan en un proceso integrativo, algunos de los cuales se comentarán a continuación:

a) Las relaciones inherentes al desarrollo de la función pueden ocasionar un spill-over o un spill-back (ramificarse o desintegrarse), El BID ejecuta estos mecanismos por medio de:

- Financiamiento que presta, ya que cada divisa que facilita estimu-

$$
\left[\begin{array}{lll}
1 & 4 & 4
\end{array}\right]
$$


la la inversión estatal o privada en una cantidad de tres veces lo prestado, actuando su capital como una semilla.

- Reforzamiento de las entidades prestatarias, que son normalmente instituciones de fomento o bien unidades de planificación que logran una capacidad técnica, lo que les permite hacer diagnósticos e identificar nuevos campos de acción.

- La modalidad que utiliza en ciertos préstamos globales al considerar componentes de distintos sectores de educación, salud, saneamiento, etc. Ecte tipo de operaciones es una clara visión funcional de su empleo, que produce spillnover en forma simultánea en varios sectores a la vez.

b) Incremento de las transacciones, incluyendo comercio, movimiento de capital, intercambio de ideas, etc.: El movimiento de personas a través de las fronteras se cumple con los consultores y con el mismo personal técnico del Banco que se desempeña en países que requieren de conocimientos tecnológicos o apoyos en áreas diferentes de la economía. Con respecto al movimiento de capitales, el BID lo realiza facilitando su propio capital a los países y en una función catalizadora, porque sus bonos son transados en los mercados financieros internac'onales. Hasta 1986 había movilizado en préstamos y cooperaciones técnicas más de us\$ 35.000 millones. E1 intercambio de ideas lo hace a través de estudios de diferentes sectores que realiza y que después difunde a sus miembros, en la forma de foros, mesas redondas, publicacione y a través de su organismo especializado en integración, el Instituto parạ la Integración Lat'noamericana.

c) Formación de grupos regionales: Coopera en la formación de grupos regionales relacionados con el desarrollo económico en América Latina.

Su interés ei crear más medios para el desarrollo. Así coopera en grupos regionales como:

- La Corporación Andina de Fomento.

- El Fondo Internacional para el Desarrollo Agrícola.

- Banco de Desarrollo del Caribe.

- Fondo Financiero de la Cuenca del Plata.

d) La socialización de las élites: Este mecanismo está referido a que en la medida que aumente la participación de la burocracia nacional en el proceso integrativo se concitará un mayor apoyo a este tipo de proceso. ¿Por qué buscar el apoyo de las burocracias nacionales? Porque estas son las más preocupadas de perder el control sobre los problemas nacionales; por lo tanto si ellas lo apoyan, pue- 
den neutralizar a las fuerzas que se opongan a la integración. A fines de la década del 50 la coincidencia de los perfiles ideológicos de los partidos políticos latinoamericanos hizo que se elaborara un conjunto de ideas comunes sobre el desarrollo a nivel político, y cuando el Presidente de Brasil presentó la Operación Panamericana, ésta fue respaldada por todos Ios miembros del sistema.

La Operación Panamericana fue un antecectente decisivo para la socialización de las élites, porque no sólo se hicieron partícipes de las necesidades y objetivos que se buscaban, sino además lograron el apoyo norteamericano.

Entre los intelectuales destacados que concitan este apoyo están Felipe Herrera, Raúl Prebisch y Antonio Mayobre; y entre los organismos que también influyen positivamente debe mencionarse a la CEPAL.

e) Participación de actores externos en el proceso: La naturaleza especial del BID hace que desde sus inicios se integre coordinadamente dentro de un cuadro en que participan otros mecanismos de cooperación económica de alcance internacional, regional o subregional como la FAO, ort, OEA y BANGo Mundial. El ingreso de actores externos, como fueron los países europeos, Israel y Japón le dio al BID la oportunidad de agregar al proceso integrativo una dimensión multilateral.

El análisis de estos mecanismos permite concluir que el BID es un organismo de cooperación internacional, cuyo desarrollo y aplicación de políticas y operaciones se ha empleado los mecanismos funcionalistas descritos.

\section{EL Convento Coństitutivo}

I. Estructura de poder: EI Artículo vII del Convenio Constitutivo regula Ia organización y administración del Banco. Su estructura superior está compuesta por:

-Asamblea de Gobernadores: Entre otras, sus tareas fundamentales son:

- Admitir nuevos miembros.

- Aumentar o disminuir el capital ordinario autorizado.

- Elegir Presidente del Banco.

- Suspender a un país miembro, etc.

Se·reúne una vez al año o cuando le convoque el Director Ejecutivo. La Asamblea está constituida por Ios representantes de cada país, que son Ministros de Hacienda y/o Presidentes de los Bancos Centrales. 
- Directorio Ejecutivo: Es responsable de la conducción de las operaciones del Banco. Está conformado por:

- Un Director designado por E: tados Unidos.

- Dos Directores elegidos por países extrarregionales.

- Ocho Directores elegidos por los otros miembros (latinoamericanos-caribeños).

Duran en sus puestos tres años y pueden elegir un suplente.

- Presidencia: Es la encargada de los negocios ordinarios y de la Administración del Personal del Banco. El Presidente del Banco preside las reuniones del Dirertorio Ejecutivo, votando sólo cuando hay empate entre sus Directores.

Los acuerdos se obtienen por mayoría de la totalidad de los votos emitidos de los países miembros. A cada país le corresponde un número de votos de ácuerdo a su capital accionario. En la Asamblea de Gobernadores los acuerdos de política son votados emitiendo cada pa's el número de votos que posee. En el Directorio Ejecutivo el Director designado por Estados Unidos emite el número de votos de su país. Los Directores elegidos emiten el total de votos que contribuyeron a su elección.

2. Sus operaciones: Todo proyecto financiado por el BD es sometido a una evaluación técnica, institucional, financiera-económica y jurídica, de acuerdo a parámetros preestablecidos. Para aprobar un proyecto se basan en consideraciones técnicas, pero se han dado interferencias políticas como en el caso de Nicaragua, donde por oposición norteamericana no se aprueba un proyecto agropecuario desde 1982 y un debate sobre Ghile durante el gobierno del Presidente Salvador Allende, en que Estados Unidos se oponía a conceder financiamiento por problemas de la nacionalización del cobre.

Los proyectos tienen una fase técnica en que intervienen especialistas del Banco que evalúan el proyecto y una fase de discusión con dos debates en el Directorio que determina si el proyecto puede pasar a la Reunión Formal. Aprobado, se discute en la Reunión Formal, donde se aprueba o rechaza el proyecto.

3. Estructura de recursos: Los recursos están compuestos por capitales ordinarios e interregionales que están conformados por acciones de us $\$ 10.000$ cada una. Sólo pueden suscribir las acciones los gobiernos de los países miembros cuyo $50 \%$ del capital se integra en efectivo y el $50 \%$ restante es capital exigible en el caso que el Banco no pueda cancelar sus obligaciones en los mercados de capital. Otros recursos son el Fondo de Operaciones Especiales, que son contribuciones de los socios, cuya compo ición es $50 \%$ en moneda nacional y $50 \%$ en oro o dólares norteamericanos. Esta es una 
modalidad funcional, porque son préstamos concesionarios en condiciones más favorables que las que rigen para otros créditos en cuanto a tasas de interés, plazo y períodos de gracia.

Lad otra fuente de recursos la constituyen los Fondos de Administración, que son entregados por países u organizaciones gubernamentales. o no-gubernamentales que tienen la característica de no constituir el capital accionario, pudiendo ser utilizados para participar conjuntamente con los recursos del Banco. Existen numerozos fondos, entre los cuales se pueden mencionar el Fondo de Canadá, de Venezuela, Suiza, Suecia, Reino Unido, el Vaticano, etc. El primer Fondo en Administración fue el Fondo Fiduciario de Progreso Social otorgado por Estados Unidos, que dio origen al Informe de Progreso Económico y Social, el cual tiene gran importancia en los medios académicos por su visión sobre la economía latinoamericana y por la seriedad de su información; no obstante es uno de los documentos cuestionados por la actual administración norteamericana.

4. Los cambios én la estructura ide poder: Desde 1960 hasta 1972, fecha en que ingresa Canadá, Ios países latinoamericanos y del Caribe tenían el 60\% del poder de votación y Estados Unidos el $40 \%$ restante. Al ingre o de Canadá los países latinoamericanos y deI Caribe dịsminuyen a un $54 \%$, Estados Unidos a $39,6 \%$ y Canadá adquiere un $6 \%$.

El poder de votación vuelve a variar con el ingreso de los paises extrarregionales, quedando los países latinoamericanos y del Caribe con un $53,93 \%$, Estados Unidos con un $34,5 \%$, Canadá con $4,39 \%$ y los extrarregionales con el $7,17 \%$.

Estas modificaciones no hicieron variar la estructura de poder, siendo a la fecha el único organismo financiero multilateral en donde el poder decisional se encuentra en manos de sus prestatarios.

5. El peso relativo de la Presidencia del Banco: Desde 1960 a 1971 ejerce la presidencia el economista Felipe Herrera, quien como máxima autoridad imprimió su sello personal, que consistía en negociar en forma directa con los Gobernadores los problemas de política o de aumento de capital, de tal forma que cuando el tema era tratado en forma oficial en la Asamblea o en el Directorio Ejecutivo todo estaba acordado con anterioridad. Gobernó el Banco sin contrapeso de tipo político. En términos organizacionales se puede decir que su presidencia fue autócrata por la subordinación del Directorio Ejecutivo, por la subordinación de la administración superior del Banco, porque él los había contratado, y por la mayor igualdad del peso relativo de los parses miembros en las decisiones de sus organismos superiores.

A partir de 1971 el Banco es pre:idido por Antonio Ortiz Mena, 
quien encuentra un entorno distinto, porque debe dirigir el Banco en medio de dos crisis económicas en que las corrientes de financiamiento internacional pierden su importancia, la cooperación internacional tiende a debilitarse y Estados Unidos adquiere mayor interés en controlar el Banco. Ante esto Ortiz Mena ha entregado la administración del Banco al Vicepresidente, dedicando un mayor tiempo a las relaciones externas para tomar una posición de defensa del latinoamericanismo del Banco frente al control excesivo que quiere tomar Estados Unidos. Estos hechos han significado que la Asamblea de Gobernadores y su Comité Ejecutivo hayan adquirido una mayor cuota de poder en la aotualidad.

La estructura de poder del BID decde el punto de vista teórico ha sufrido modificaciones conceptuales; es así como durante la administración del Presidente Eisenhower se adopta una serie de polfticas de cooperación que dan origen a la aplicación funcionalista de cooperación internacional hemisférica. En 1959 se apoya el establecimiento de una institución interamericana de desarrollo regional y posteriormente, en 1961, bajo la administración del Presidente Kennedy, la Alianza para el Progreso.

Esta visión funcionalista de la cooperación internacional perduró diez años, logrando para Latinoamérica un mejoramiento en los niveles sociales y económicos, hasta que en 1969, durante Ia administración deI Presidente Nixon, cambia nuevamente la interpretación y recomendación de los mecanismos integrativos a un modelo bajo la teoría realista químicamente pura, siendo el slogan de esa época, "Trade Not Aid". El interés del Presidente Nixon para que ingresen como miembros del Banco los países extrarregionales descarta la visión funcionalista de la cooperación hemisférica como algo de trascendencia para convertirla en un asunto irrelevante, colocando al BID y a sus miembros regionales en una visión globalista de tipo estratégica, exigiendo a sus aliados europeos que así como tenían una cuota de responsabilidad en los problemas -de seguridad Este-Oeste participen en la cooperación hemisférica, que curio:amente dejaba de ser hemisférica, bajo la visión realista que se implantaba nuevamente.

Esto afectó y debilitó el esquema integrativo de la región, pero el rol del BID se mantuvo como principal organismo financiero regional, manteniendo el apoyo a las políticas de desarrollo de sus países miembros regionales, gracias a que este nuevo ingrezo no alteró la composición de-su estructura decisional.

En el espacio de diez años se producen dos aproximaciones distintas para un mismo problema: la visión funcionalista del Presidente Kennedy y la posición realista del Presidente Nixon. Pero consi- 
derando su actuación en el tiempo, el BID no perdió su caracteristica multilateral y orientación funcional.

VI. LA GRISIS ECONÓMICA INTERNAGIONAL $\mathbf{Y}$ SU INCIDENGIA EN EL BID

1. La deuda externa: El elevado nivel de liquidez del sistema financiero internacional a mediados de la década del 70, motivadó por el reciclaje de los petrodólares, hizo que los créditos externos fueran relativamente baratos y fáciles de obtener, Io cual alentó a los países a financiar su déficit de la balanza de pagos y en la mayoría de los casos a aumentar sus reservas sin tener que recurrir a las devaluaciones monetarias.

En 1982 y 1983, motivada por la recesión internacional, se produce una reducción de entradas de capital por disminución de la inversión extranjera y cayeron las reservas a niveles críticos.

La Banca Comercial, ante la gravedad de la crisis cortó el ṭlujọ crediticio, aceptando mantener las líneas de crédito abiertas siempre que los países deudores se sometieran a programas de ajuste bajo la guía del FMr.

Los programas consistieron en una drástica reducción de los gastos públicos, medidas antinflacionarias, aumento de los impuestos y políticas para evitar la fuga de capitales. Estos programas fueron impopulares, creando desórdenes políticos, porque bajaron los aportes públicos para proyectos sociales y lo más grave es que se originaron masas de desempleados, que fueron creciendo a tasas nunca vistas desde la crisis de los años 30 .

Los líderes de los gobiernos comenzaron a decir que la región no podía sacrificar su crecimiento para pagar los us $\$ 300$ mil millones de deuda externa. En 1982 viene el colapso financiero mexicano y seis meses después el Presidente de Ecuador, Osvaldo Hurtado, solicita a GEPAL y SELA que desarrollen una estrategia para poder negociar la deuda. En enero de 1984, en Quito, Ecuador, se realiza una conferencia económica latinoamericana con asistencia de 26 países, y de ella surge un documento que indicaba los pasos por seguir para facilitar los problemas de la región.

En mayo de 1984 la tasa Prime hizo aumentar en millones de dólares la deuda externa. Se reunieron entonces los Presidentes de Argentina, Brasil, Colombia y México para solicitar a los países industrializados que adoptaran actitudes más flexibles.

A mediados de 1984 se forma el Grupo de Cartagena, institucionalizando a once países latinoamericanos en un foro regional permanente para consultas sobre materias de la deuda externa, que se reúnen posteriormente, en septiembre de 1984, en Mar del Plata y 
en febrero de 1985 en Santo Domingo, siempre invitando a los patses industrializados a buscar soluciones de largo plazo.

Entre 1982 y 1984 el gobierno norteamericano no le dio mayor importancia a los planteamientos latinoamericanos, por cuanto consideraba que $\mathrm{I}_{\mathrm{a}}$ crisis había sido manejada satisfactoriamente, ya que no había corrido un riesgo el sistema financiero internacional. E1 8 de octubre de 1985 se efectúa una reunión en Corea de los gobernadores del Banco Mundial, donde el Secretario del Tesoro, James Baker, formula la propuesta conocida como el Plan Baker. El proyecto es un llamado a los bancos comerciales a expandir sus préstamoj a los países más endeudados de Latinoamérica, Asia y Africa por un monto de us $\$ 20.000$ millones y el FMr, Banco Mundial y otros organismos financieros internacionales aportarían igualmente us $\$ 9.000$ millones. Posteriormente, en abril de 1986, el senador R. A. Bill Bradly hace otra proposición de crear un Consejo de Siete Miembros que coordine la acción de la banca privada acreedora con los gobiernos deudores a fin de evaluar las propuestas de crecimiento de los países deudores y así operar con soluciones de crecimiento.

Esta crisis está en pleno desarrollo y se pueden obtener ciertas conclusiones de las diferentes posiciones:

a) Tanto el Consenso de Cartagena como la proposición del Senador Bradly, han logrado que el tema de la deuda externa sea tratado en los foros internacionales, permitiendo que las negociaciones políticas recién estén comenzando, en el marco de un proce: o que puede continuar hasta fines de la presente década.

b) El Plan Baker no ha conseguido la participación de la banca privada, quien está más intere ada en recuperar los préstamos. Esto ha mantenido a Latinoamérica en una virtual marginación de los flujos financieros privado.

c) Las medidas de ajustes impuestas a los latinoamericanos han significado grandes problemas sociales que han repercutido en la intranquilidad política de estos países. El sacrificio solicitado no es compartido, ya que la percepción latinoamericana culpa de la actual crisis al déficit fiscal norteamericano, al alto valor de las tasas de interés, a la poca estabilidad del dólar americano en los mercados internacionales, a la disminución y casi nula corriente voluntaria de financiamiento externo y al nuevo proteccionismo de los países industrializados.

d) En el período 1982-86 América Latina transfirió recursos netos por Us $\$ 132.000$ millones. En 1985 la banca multilateral apoyó con los dos tercios del financiamiento externo de la región y el BID, que en la década del 70 aportó como promedio un $4 \%$ del financiamien- 
to externo de la región, en 1985 se responsabilizó con un $30 \%$ del mismo.

Lo que interesa destacar de esta crisis es que la mayor presencia relativa de este aporte se debe al fuerte desfinanciamiento privado. El aporte de la banca multilateral no es suficiente para las necesidades reales, debido como en el caso del BID, al impasse surgido en la vir reposición. Estados Unidos contribuye actualmente con el $72 \%$ de los recursos del BID y posee sólo el $34 \%$ del poder de votación, condicionando una recapitalización al cambio de la estructura decisional del Banco.

Estados Unidos no puede proponer un cambio que modifique el Convenio Constitutivo, porque ello significaría que todos los países deberían volver a realizar un trámite de aprobación legislativo. Por ello propuso hacer ciertos ajustes en los mecanismos de decisión a nivel del Directorio Ejecutivo y en la administración interna del Banco.

En el Directorio Ejecutivo desea introducir una cláusula por medio de la cual un Director con el $35 \%$ de los votos pueda retirar cualquier documento de análisis del Directorio Ejecutivo, debiendo éste ser devuelto a la Administración del Banco para su reestudio y no pudiendo ser presentado hasta transcurrido un tiempo prudencial. Si en una segunda oportunidad se vuelve a retirar el documento del Directorio Ejecutivo, éste no podrá volverse a presentar en ninguna otra ocasión.

La reorganización administrativa propuesta pretende refundir dos departamentos: el de Desarrollo Económico y Social y el de Planes y Programas. El primero realiza los estudios socio-económicos requeridos para orientación y apoyo de las actividades del Banco; el segundo coordina las actividades del. Banco en cuanto al desarrolio de proyectos de los países.

La propuesta es refundir estos dos departamentos a fin de darle un mayor énfasis a los estudios de programas por países, de manera que estos programas analicen los cambios necesarios de política económica de los países miembros, a fin de que las planificaciones de desarrollo económico sean concordantes con las prioridades del Banco. Con ello se pone una condicionalidad mucho más fuerte, muy similar a la impuesta por el FMI y el Banco Mundial con sus Programas de Ajuste Estructural. Haciendo una similitud podriamos decir que, de acuerdo con estas proposiciones, el BID cumpliría una función de rector de la economía latinoamericana controlada por Estados Unidos.

2. La VII reposición de recursos: El Banco requiere de recursos para mantener un nivel creciente de operaciones de préstamos; para 
ello reúne periódicamente a la Asamblea de Gobernadores a fin de proponer un aumento de sus recursos. Desde 1963 hasta 1987, la Administración del Banco ha planteado siete reposiciones, habiendo concedido seis. La séptima está en una impasse, por cuanto Estados Unidos, el principal accionista, se niega. a conceder mayores recursos mientras"no se adopten las modificaciones propuestas.

En la xxvir Reunión de Gobernadores en San José de Costa Rica, en marzo de 1986, la deuda externa fue el tema del foro y todas las intervenciones de los Gobernadores se refirieron a ella. Aunque no existió una posición unánime en algunos asuntos relacionados con el futuro financiero del Banco, sí la hubo en lo referente a la necesidad de presentar el carácter de organismo regional y multilateral del BID, con derecho pleno de todos y cada uno de sus miembros a participar en sus decisiones. En el período transcurrido desde la Vigesimoséptima Reunión Anual, el Comité de la Asamblea se reunió en seis oportunidades, logrando acuerdos en muchos aspectos, pero siempre existió un desacuerdo en torno al posible nuevo mecanismo de decisión a nivel de Directorio Ejecutivo.

En la XxviII Reunión de Miami, celebrada en marzo de 1987, nuevamente se hizo presente el escollo más grande de dilucidar en torno a la vir Reposición, el mecanismo de decisión. El Secretario del Tesoro planteó en sus exposicione; ante la Asamblea muy claramente: o se acepta su proposición de modificar la estructura de poder, o bien se continúa con el statu quo, no pudiendo el Banco desarrollar una función protagónica en el desarrollo latinoamericano. Este planteamiento fue rechazado y en la úitima reunión celebrada en octubre de 1987 en Guatemala, el Comité de la Asamblea se desistió de continuar las negociacione; bajo estas condiciones, surgiendo la impasse de quedar suspendidas las negociaciones para la vII Reposición, postura que es unánime de todos los miembros, con excepción de Canadá, que apoya la posición norteamericana.

\section{ConCLusiones}

I. El BID como expre ión del funcionalismo: En la década del 50 madura la idea de contar con un organismo multilateral de cooperación para el desarrollo, basada en la convicción de lo; beneficio; de la COOPERACIÓN por sobre la GONERONTACIÓN, haciendo partícipe a Estados Unidos como principal socio cooperador, sin concederle ningún tipo de poder y logrando una igualdad en el peso relativo de los distintos países en sus órganos superiores de decisión.

La creación del axD como expresión del funcionalismo es un deliberado propósito de estimular desde sus inicios los procesos de integración económica, regional y subregional en América Latina. Su 
convenio estableció el progreso económico individual y colectivo, mandato que ha cumplido fielmente, al mantener una actitud de respaldo a las iniciativas binacionales y multinacionales, especialmente en el campo de los proyectos y programas de integración física, ast como en el desarrollo de nuevas instituciones. Frente a la solución clásica que primaba en la región hasta la década del 50 y que propugnaba que los conflictos de toda índole debían ser dirimidos por la nación hegemónica, surgió esta visión funcional que creó este organismo técnico multilateral dirigido por técnicos y con marco jurídico, que puede desempeñarse como sujeto internacional con capacidad para la solución técnica de los complejos problemas gubernamentales.

Sus realizaciones en todos estos años, además de llevar a un progreso individual y colectivo, radican en afirmar la validez de la tesis funcionalista al demostrar que, cuando polf́ticos y tecnócratas se unen bajo el concepto de cooperación, sus frutos son mucho más rentables y perdurables que cuando se unen en un esquema de confrontación.

2. La evolución del BID y el funcionalismo: En 1961, cuando el Banco inicia sus operaciones, todos sus miembros estaban empapados con un espíritu de cooperación para impulsar el desarrollo económico y social de América Latina. La orientación de sus miembros era funcionalista, porque reconocían la creciente nece-idad de una colaboración técnica y funcional que traspasara las fronteras. En esta época el BID nunca tuvo una interferencia política de ningún miembro en la implantación de sus políticas de cooperación a los problemas del desarrollo.

A partir de mediados de la década del 70 comienza a desarrollarse otro tipo de cooperación económica internacional, que se contradice abiertamente con la realidad de la creciente interdependencia económica y con la visión funcionalista de la solución de los problemas. Este cuestionamiento tiene su origen en la crisis económica financiera que han debido soportar los países en de arrollo, haciendo que el Banco intervenga con mayor fuerza en la solución de los problemas que plantean las constantes necesidade; de financiamiento externo de Latinoamérica, perdiendo su sola calidad de institución de desarrollo para asumir en parte las características de un banco de financiamiento comercial.

En el actual período 1986-1988 se encuentra en juego la capacidad del Banco de continuar un rol protagónico en el desarrollo y cooperación latinoamericana y existe el peligro de perder su visión funcional, para asumir una función de instrumento de poder de Estados Unidos, que busca retomar su papel hegemónico mundial. 
3. Las perspectivas del BID en las relaciones internacionales: Los puntos fundamentales del Plan Baker eran el accionar de la banca privada comercial y del Tesoro de los Estados Unidos para el aporte de financiamiento de Ios países más endeudados, a fin de evitar la asfixia financiera y poder pagar la deuda externa.

Transcurridos dos años, el plan no se ha implementado; por el contrario, los préstamos de la banca privada han disminuido en un $8 \%$ en América Latina y ello, porque el Plan no incuye un mecanismo de poder que garantice el apoyo de la banca privada. También el Plan Baker consideraba mayores recursos para los organismos financieros internacionales, lo que no ha cumplido. Tiene la oportunidad de hacerlo en esta VII Reposición del BID, pero no lo hará, a menos que se efectúen los cambios en los mecanismos de decisión del Directorio Ejecutivo. A tal punto de inflexibilidad ha llegado la posición norteamericana, que debió renunciar su actual Presidente Ortiz Mena, ante la imposibilidad de lograr la colaboración de Estados Unidos en la reposición de los recursos del BID. Con ello abrió un proceso eleccionario entre diferentes candidatos latinoamericanos para ocupar la presidencia de este organismo internacional, dependiendo el futuro de las conversaciones del poder de negociación ante los norteamericanos que tenga el futuro Presidente. Aunque sea elegido un diplomático de vasta experiencia en materias financieras internacionales, su campo de negociación e tará igualmente limitado, porque los latinoamericanos están renuentes a admitir un cambio en los mecanismos decisionales del Banco, condición sine qua non de Estados Unidos para incrementar su aporte al BID*.

Estados Unidos, bajo esta Administración, ha vuelto a una práctica de las relaciones internacionales bajo la visión clásica o realista para retomar su papel hegemónico. La revitalización nọtteamericana se basa en el mejoramiento de la economfa mundial, la reconstrucción de su poderío militar y el reordenamiento de las relaciones internacionales. En este marco, el BID para Estados Unidos serja un instrumento de poder, ya que controlado por él, tendría un rol que antes no tenía, mucho más global e importante en la discusión y negociación en las políticas de ajuste estructural de la economía, o sea, un papel que antes cumplía el FMI.

El problema de fondo es que los latinoamericanos no han sido convencidos de que la proposición norteamericana de aumentar los recursos del BrD a cambio de venderle la autoridad sea una política sostenida y honesta. Por el contrario, la perciben como un incenti-

* Enrique V. Iglesias, ex Secretario Ejecutivo de ceral y ex Canciller de Uruguay, fue elegido Presidente del BID con posterioridad a la redacción de este ar ticulo. 
vo temporal y que, una vez aceptadas todas las operaciones, estará sometida a la aprobación de Estados Unidos. Es por ello que acceder a esta propuesta les parece como un su:cidio.

El trasfondo de toda esta situación es política y se genera en la visión clásica de la actual Administración, que ha adoptado un rol dominante para ejercer un grado de influencia concordante con la obtención de los objetivos de su política externa.

Así sé concluye que el escenario más probable será la mantención de la situación actual y, debido a que el Banco aún posee recursos disponibles de la anterior reposición de capital, podrá seguir funcionando por cuatro años más. Se podría volver a una situación normal si hay un cambio en el liderato de la Admini tración norteamericana en la próxima elección presidencial. 